\title{
A very early diagnosis of Alström syndrome by next generation sequencing
}

\author{
Leonardo Gatticchi ${ }^{1}$, Jan Miertus ${ }^{2,3}$, Paolo Enrico Maltese ${ }^{3^{*}}$ (D) Simone Bressan ${ }^{3}$, Luca De Antoni ${ }^{4}$,

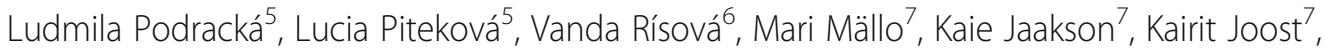 \\ Leonardo Colombo ${ }^{8}$ and Matteo Bertelli, ${ }^{3,4}$
}

\begin{abstract}
Background: Alström syndrome is a rare recessively inherited disorder caused by variants in the ALMS1 gene. It is characterized by multiple organ dysfunction, including cone-rod retinal dystrophy, dilated cardiomyopathy, hearing loss, obesity, insulin resistance, hyperinsulinemia, type 2 diabetes mellitus and systemic fibrosis. Heterogeneity and agedependent development of clinical manifestations make it difficult to obtain a clear diagnosis, especially in pediatric patients.

Case presentation: Here we report the case of a girl with Alström syndrome. Genetic examination was proposed at age 22 months when suspected macular degeneration was the only major finding. Next generation sequencing of a panel of genes linked to eye-related pathologies revealed two compound heterozygous variants in the ALMS1 gene. Frameshift variants c.1196_1202del, p.(Thr399Lysfs*11), rs761292021 and c.11310_11313del, (p.Glu3771Trpfs*18), rs747272625 were detected in exons 5 and 16, respectively. Both variants cause frameshifts and generation of a premature stop-codon that probably leads to mRNA nonsense-mediated decay. Validation and segregation of ALMS1 variants were confirmed by Sanger sequencing.

Conclusions: Genetic testing makes it possible, even in childhood, to increase the number of correct diagnoses of patients who have ambiguous phenotypes caused by rare genetic variants. The development of high-throughput sequencing technologies offers an exceptionally valuable screening tool for clear genetic diagnoses and ensures early multidisciplinary management and treatment of the emerging symptoms.
\end{abstract}

Keywords: Alström syndrome, ALMS1, Next generation sequencing, Case report

\section{Background}

Alström syndrome (AS; OMIM \#203800) is a rare recessively inherited disorder caused by loss-of-function variants in the ALMS1 gene [1]. It is typically associated with early onset and rapid development of cone-rod retinal dystrophy, usually with nystagmus and strong photophobia. Retinal degeneration may also be accompanied by dilated cardiomyopathy, congestive heart failure and bilateral sensorineural hearing impairment $[2,3]$. Other clinical manifestations

\footnotetext{
* Correspondence: paolo.maltese@assomagi.org

${ }^{3}$ MAGI's Lab, Genetic Testing Laboratory, Via Delle Maioliche 57/D, 38068 Rovereto, TN, Italy

Full list of author information is available at the end of the article
}

progress slowly, leading to multiple organ dysfunction due to the concurrence of metabolic complications like obesity, insulin resistance, hyperinsulinemia, dyslipidemia and type 2 diabetes mellitus, as well as widespread fibrosis that can lead to kidney, respiratory, pancreatic and liver failure [4-6].

ALMS1 is a 23-exon gene located on chromosome 2 p13; it encodes a ubiquitously expressed protein product associated with the centrosome and basal body of primary cilia $[7,8]$. Recent studies on the functions of ALMS1 suggest that AS is in the class of human genetic disorders linked to ciliary dysfunction, known as ciliopathies [9-11]. In fact, ALMS1 seems to be required for correct formation and function of primary cilia. Cilia are hair-like cell

(c) The Author(s). 2020 Open Access This article is licensed under a Creative Commons Attribution 4.0 International License, which permits use, sharing, adaptation, distribution and reproduction in any medium or format, as long as you give appropriate credit to the original author(s) and the source, provide a link to the Creative Commons licence, and indicate if changes were made. The images or other third party material in this article are included in the article's Creative Commons licence, unless indicated otherwise in a credit line to the material. If material is not included in the article's Creative Commons licence and your intended use is not permitted by statutory regulation or exceeds the permitted use, you will need to obtain permission directly from the copyright holder. To view a copy of this licence, visit http://creativecommons.org/licenses/by/4.0/ The Creative Commons Public Domain Dedication waiver (http://creativecommons.org/publicdomain/zero/1.0/) applies to the data made available in this article, unless otherwise stated in a credit line to the data. 
projections that occur in many types of cell and are involved in the sensory processes of terminally differentiated cells, through special signaling transduction pathways [12-14]. The exact function of ALMS1 is being studied but roles in cytoskeleton and microtubule organization, endosomal and ciliary transport, cell cycle regulation of neonatal cardiomyocytes, and blood pressure and renal homeostasis were recently proposed [4, 15-21]. However, isoforms of ALMS1 with non-centrosomal sites of localization have been described, suggesting extra-ciliary functions as well [22-25].

The pleiotropic array of functions displayed by ALMS1 in a variety of different cell types may partly explain the heterogeneous clinical manifestations of AS, which in the end make it difficult to obtain a clear diagnosis, especially in children. The current diagnostic criteria for AS require a combination of major and minor features, according to the age of onset [3]. Indeed, the phenotype of AS partly overlaps with that of the other main ciliopathy, BardetBiedl syndrome (BBS), and differential diagnosis is often made by excluding clinical manifestations specific to BBS [26]. Atypical cases with non-syndromic retinal dystrophy or isolated cardiomyopathy due to variants in ALMS1 have also been reported [27, 28]. The development of high-throughput sequencing technologies, such as wholegenome or exome sequencing, offers an exceptionally valuable screening tool for obtaining clear genetic diagnoses and identifying disease-causing gene variants. To date, about 1000 cases of AS have been confirmed worldwide, making a prevalence of 1-9 per million individuals (http://www.orpha.net). More than 200 variants in ALMS1 have been described, mainly involving frameshift or nonsense variants that introduce premature stop codons [29]. Most of the ALMS1 variants detected are clustered in exons 8 (49\% of all known variants), 10 and 16 [29-33], although other variants have been reported in exon 5 [34$36]$ and others in intronic regions [29, 33, 37, 38].

Here we report the case of a 22-month-old girl with Alström syndrome. Early genetic diagnosis was achieved by an optimized next generation sequencing approach, targeting a panel of genes linked to eye-related pathologies that revealed two compound heterozygous variants in the ALMS1 gene. The importance of preemptive genetic screening and future prospects for treating Alström syndrome are also discussed.

\section{Case presentation}

The proband was born at term (week 39) by caesarean section due to fetal position, without complications (Apgar score at $\left.5^{\prime}=10\right)$. Weight $(2720 \mathrm{~g})$, length $(47 \mathrm{~cm})$ and head circumference $(33 \mathrm{~cm})$ were normal. Subsequent growth and development were normal (e.g. $\mathrm{w}=5970 \mathrm{~g}, \mathrm{l}=$ $61 \mathrm{~cm}, \mathrm{hc}=40.5 \mathrm{~cm}$ at 4 months). A small jugular hemangioma was noticed at age 6 months by the pediatrician. The infant recovered from several episodes of acute bronchitis that have continued to exacerbate. At age 1 year an ophthalmologist was consulted because her parents noticed photophobia (squinting) and random hitting of objects. The specialist suspected macular degeneration and found convergent concomitant strabismus of the right eye. Fluorescein angiography showed a patchy hyperfluorescent fundus, adequate filling of the vascular bed, macula with thinner or centrally patchy retinal pigmented epithelium with surrounding spots/patches of window-type defect and initial "bull's eye" features, in line with a diagnosis of maculopathy or cone dystrophy.

At age one year, the infant contracted acute Haemophilus influenzae-positive pneumonia. At age 22 months genetic examination was proposed.

Genomic DNA was extracted from $200 \mu \mathrm{l}$ whole blood using a QIAamp DNA Mini Kit (Qiagen GmbH, Hilden, Germany). Library preparation and sample enrichment were performed with an Illumina TruSight One kit. Next generation sequencing (NGS) was performed on an Illumina NextSeq 500 system (Illumina, San Diego, CA, USA). Variants differing from hg19 reference sequence were called with BWA2.1 in Illumina BaseSpace. Data annotation for 277 genes associated with hereditary eye diseases was performed with programs Varvis (Limbus Medical Technologies GmbH, Germany) and Alamut Visual (Interactive Biosoftware, France) and rare variants (frequency less than $1 \%$ ) were filtered. Pathogenic variants of human ALMS1 (RefSeq: NM 015120.4) were confirmed with PCR and Sanger sequencing on a 3730xl DNA analyser (Applied Biosystems, Foster City, CA, USA). Sequences were analysed with BioEdit (Ibis Therapeutics, CA, USA) and ChromasPro (Technelysium Pty Ltd., Australia). Genetic variants were submitted to the Human Gene Mutation Database (HGMD), Leiden Open Variation Database (LOVD), 1000 Genome Project and the Exome Aggregation Consortium (ExAC) database. The pathogenicity of each variant was checked using the on-line software VarSome (https://varsome.com/) [39]. Because of the non-specificity of the clinical picture and diagnosis, all 277 "eye exome" genes were tested: $A B C A 4, A B C B 6, A B C C 6, A B H D 12, A C B D 5$, ADAM9, ADAMTS18, ADGRV1, AGK, AHI1, AIPL1, ALMS1 (excluding exon 8), ARL13B, ARL6, B3GLCT, BBS1, $B B S 10, B B S 12, B B S 2, B B S 4, B B S 5, B B S 7, B B S 9, B C O R$, BEST1, BFSP2, BMP4, C19ORF12, C1QTNF5, C2orf71, C8ORF37, CA4, CABP4, CACNA1F, CACNA2D4, CC2D2A, CDH23, CDH3, CDHR1, CEP290, CEP41, CERKL, CFH, CHM, CHMP4B, CHST6, CIB2, CLN3, CLN5, CLN6, CLN8, CLRN1, CNGA1, CNGA3, CNGB1, CNGB3, CNNM4, COL11A1, COL11A2, COL2A1, COL4A1, COL8A2, COL9A1, COL9A2, CRB1, CRX, CRYAA, CRYAB, CRYBA1, CRYBA4, CRYBB1, CRYBB2, CRYBB3, CRYGB, CRYGC, CRYGD, CRYGS, CTDP1, CTSD, CYP1B1, CYP4V2, DCN, DHDDS, EFEMP1, ELOVL4, EPHA2, EYS, FAM161A, FLVCR1, FRAS1, FREM1, FREM2, FSCN2, FTL, FYCO1, FZD4, 
GALK1, GALT, GDF3, GDF6, GFER, GIPC3, GJA1, GJA3, GNAT1, GNAT2, GNPTG, GPR143, GPR179, GRIP1, GRK1, GRM6, GRN, GSN, GUCA1A, GUCA1B, GUCY2D, HARS, HCCS, HMX1, HSF4, IDH3B, IFT140, IMPDH1, IMPG2, INVS, ITM2B, IQCB1, JAG1, JAM3, KCNJ13, KCNV2, KIF11, KIF7, KLHL7, KRT12, KRT3, LAMA1, LCA5, LIM2, LRAT, LRP5, LZTFL1, MAK, MERTK, MFN2, MFRP, MFSD8, MIP, MKKS, MKS1, MTTP, MVK, MYOTA, MYOC, NAA10, NDP, NHS, NMNAT1, NPHP1, NPHP3, NPHP4, NR2E3, NRL, NYX, OAT, OFD1, OPA1, OPA3, OPN1MW, OTX2, PANK2, PAX2, PAX6, PCDH15, PDE6A, PDE6B, PDE6C, PDE6G, PDE6H, PDZD7, PEX7, PHYH, PIKFYVE, PITP NM3, PITX2, PITX3, PLA2G5, PPT1, PRCD, PRDM5, PROM1, PRPF3, PRPF31, PRPF6, PRPF8, PRPH2, PRSS56, RAB28, RAX2, RBP3, RBP4, RD3, RDH12, RDH5, RGR, RGS9, RGS9BP, RHO, RIMS1, RLBP1, ROM1, RP1, RP1L1, RP2, RP9, RPE65, RPGR (excluding ORF15), RPGRIP1, RPGR IP1L, RS1, SAG, SDCCAG8, SEMA4A, SIX6, SLC24A1, SLC45A2, SLC4A11, SMOC1, SNRNP200, SOX2, SPATA7, STRA6, TACSTD2, TCTN1, TCTN2, TDRD7, TEAD1, TGFBI, TIMM8A, TIMP3, TMEM126A, TMEM138, TMEM216, TMEM237, TMEM67, TOPORS, TPP1, TREX1, TRIM32, TRPM1, TSPAN12, TTC21B, TTC8, TULP1, TYR, TYRP1, UBLAD1, UNC119, USH1C, USH1G, USH2A, VAX1, VCAN, VIM, VPS13B, VSX1, VSX2, WDPCP, WDR19, WFS1, WHRN, YAP1, ZEB1, ZNF469, ZNF513, ZNF644.

The proband's parents agreed to this genetic test and signed written informed consent to use of the anonymized clinical and genetic results for research. All genetic and clinical data was collected as part of routine diagnosis and does not require ethical approval.

Genetic testing revealed two compound heterozygous variants of the ALMS1 gene in trans conformation: i) a paternally inherited deletion in exon 5 c.1196_1202del, p.(Thr399Lysfs*11), rs761292021; ii) a maternally inherited deletion in exon 16 c.11310_11313del, (p.Glu3771Trpfs*18), rs747272625 (Fig. 1). The first variant results in an amino acid substitution of residue 399 (Thr/Lys) and a frameshift leading to the creation of a premature stop codon after 11 residues. The second variant produces a similar result, characterized by a Glu/Trp substitution at position 3771 and generation of a premature stop codon after 18 residues. Validation and segregation of the ALMS1 variants were confirmed by Sanger sequencing. A healthy 5 -year-old sister of the proband tested negative to segregation analysis. DNA sequencing of the proband and the related summary of the 277 "eye exome" genes can be found as Additional files 1 and 2 respectively; Sanger sequencing data of the proband and their relatives can be found as Additional file 3.

On diagnosis of Alström syndrome, a very detailed report of the significance of this result was prepared (posttest genetic counselling) and a specific preventive diagnostic plan was formulated. The infant then underwent cardiological examination: ultrasonography showed borderline heart dimensions for weight, decreased function of left ventricle, no signs of true dilative cardiomyopathy or heart failure; no therapy but monitoring every 6-12 months was prescribed; picture unchanged after 1 year. Neurological examination was initially normal; since follow-up at age 3 years showed continued need of diapers, urological evaluation was proposed. Linguistic and graphic apraxia (intellectual disabilities) subsequently appeared with attention deficit and hyperkinetic behaviour; flat feet were recorded. Routine blood tests showed hypercholesterolemia (total $\mathrm{Ct}=5.02 \mathrm{mmolL}^{-1}$ ) and hypertriglyceridemia $\left(1.74 \mathrm{mmolL}^{-1}\right)$ as defined by levels superior than $4.8 \mathrm{mmolL}^{-1}$ and $1.64 \mathrm{mmolL}^{-1}$, respectively; a low calorie, low fat, omega-3 rich diet was proposed. Ear, nose and throat evaluation showed chronic catarrhal inflammation of the middle ear ("glue ear": the mother retrospectively reported having to raise her voice to speak to her daughter) treated with surgical fitting of grommets. Lung evaluation showed bronchial asthma to be treated with beta-mimetics and antibiotics if needed; electron microscope histopathological examination of a

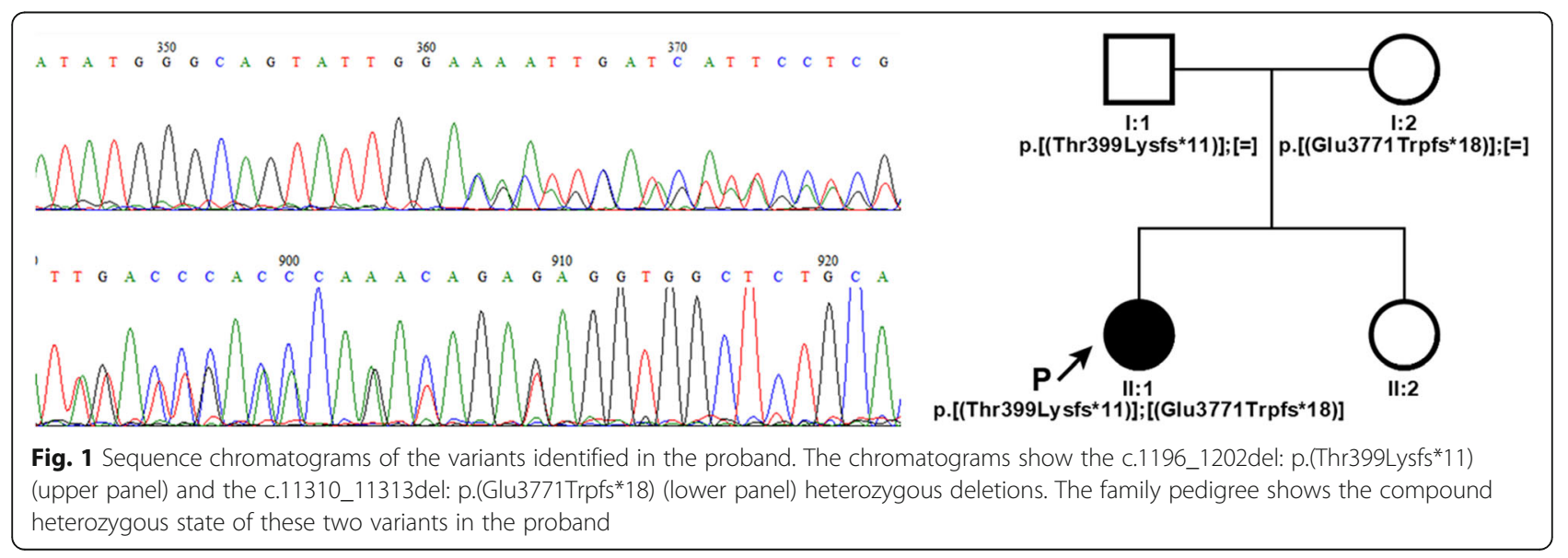


laryngobronchoscopy biopsy specimen showed a decreased number of cilia, many substituted by microvilli (basal corpuscle present), normal microtubule conformation and conserved dynein forks. The ophthalmologist prescribed dark orange glasses with correction for hypermetropia $(+4 \mathrm{D} /+3 \mathrm{D})$ and astigmatism. Perigenital mycosis developed at a later age.

\section{Discussion and conclusions}

Alström syndrome (AS) is a rare multisystemic disorder caused by mutations in the ALMS1 gene. Clinical manifestations include onset of cone-rod retinal degeneration in the first year of life. The retinal dystrophy usually progresses to bilateral blindness and may be accompanied by additional phenotypes like dilated cardiomyopathy, hearing loss, obesity, severe insulin resistance and type 2 diabetes mellitus. Although the incidence of these complications is high, AS patients develop the various symptoms in an age-dependent manner, in some cases in early infancy but usually in childhood or adolescence. Retinal dystrophy is usually the first sign that draws attention to AS, although non-syndromic retinal dystrophy has been reported in association with $A L M S 1$ variants [27], or in association with hearing loss mimicking Usher syndrome, the most prevalent form of syndromic retinitis pigmentosa to consider for differential diagnosis [40]. It is therefore difficult to diagnose AS in its early stages relying exclusively on clinical manifestations. This precludes affected individuals from obtaining prompt and targeted treatment. The implementation of genetic testing in clinical practice makes it possible to increase the number of correctly diagnosed patients among those with ambiguous phenotypes caused by rare genetic variants. The development of high-throughput sequencing technologies has enabled clinicians to obtain fast and accurate genetic diagnoses and ensures early multidisciplinary management and treatment of the emerging symptoms.

In this case report of a child with AS by next generation sequencing of a panel of genes linked to eyerelated pathologies, the patient was very young (22 months) and did not show any very specific clinical phenotypes, except central loss of visual acuity and accentuated photophobia. We investigated a list of known gene variants associated with degenerative eye diseases. The list can be optimized to include new gene variants or adapted to different groups of disorders by the same approach. Genetic screening of the patient identified two compound heterozygous frameshift variants in ALMS1. This established the diagnosis of AS, coherently with our preliminary observation of a slight elevation in body mass index. The first variant p.(Thr399Lysfs*11) was detected in exon 5, the second (p.Glu3771Trpfs*18) in exon 16. Both cause frameshifts that introduce a premature termination codon, like the majority of ALMS1 variants reported so far $[29,30]$. ALMS1 is a long protein of 4167 amino acids. The deletion in exon 5 causes a frameshift at residue 399 and produces a premature stop codon at residue 411, which presumably triggers nonsense-mediated mRNA decay [41]. The variant was recently reported in two brothers with an atypical form of AS [42]. The three basepair deletion in exon 16 is a known AS variant [29] that causes frameshift at residue 3771 and premature termination at residue 3789 , suggesting production of an aberrant protein product lacking the Cterminal domain, which could possibly impair centrosomal localization of ALMS1, as previously reported for other variants [19]. However, in the absence of an analysis of the protein product we cannot exclude that this variant, too, leads to mRNA decay.

Being a pleiotropic disease, treatment of the manifestations of AS requires multidisciplinary management. Useful guidelines for disease management, listing the necessary evaluations after initial diagnosis and therapeutic measures, can be found in GeneReviews ${ }^{\circ}$ [43]. In brief, since cone-rod dystrophy evolves to complete blindness, early education in orientation and mobility and in the use of Braille is essential to master independent living skills. Hearing loss can be treated with digital hearing aids and cochlear implants. Skeletal complications, often scoliosis, require adequate physiotherapy.

Besides other manifestations, AS results in obesity, severe insulin resistance and dyslipidemia. Through appropriate lifestyle modifications, such as a healthy lowcalorie, low fat diet and plenty of physical activity, resulting in weight reduction, it is possible to improve glucose control and serum lipids, lowering the risk of type 2 diabetes, metabolic syndrome and also cardiovascular disease [44-46]. In addition to non-pharmacological management, pharmacological treatments such as statins for managing dyslipidemia [47], ACE-inhibitors in patients with hypertension or left ventricle dysfunction [48] and metformin therapy may be considered for the prevention of type 2 diabetes [49].

Developmental disability needs to be assessed on a case-by-case basis and often requires specialist support from a developmental pediatrician or a pediatric psychiatrist. Good clinical follow-up and full family support can maximize the possibilities of integration in society and educational and employment opportunities.

In conclusion, diagnosis of a very young patient with AS through next generation sequencing offers an example of this method as an exceptionally valuable screening tool for the correct diagnosis patients, especially children, when clinical data is not sufficient for a 
clear diagnosis. Although whole exome sequencing has proved very useful for accurate early diagnosis of AS [50], the optimization of screening panels based on patient manifestations and the literature may reduce the need for massive screening.

Early genetic diagnosis based on a sensitive and relatively low cost approach allows clinicians to determine the best available therapeutic options without delay, which can be crucial in invalidating rare genetic disorders like AS.

\section{Supplementary information}

Supplementary information accompanies this paper at https://doi.org/10. 1186/s12881-020-01110-1.

Additional file 1.

Additional file 2.

Additional file 3.

\section{Abbreviations}

AS: Alström syndrome; BBS: Bardet-Biedl syndrome; Ct: Cholesterol

\section{Acknowledgements}

Not applicable.

\section{Authors' contributions}

LG made substantial contributions to the conception of the work and was a major contributor in writing the manuscript. JM performed genetic counselling and clinical examinations, collected the patient data and was a major contributor in writing the manuscript.. PEM was a major contributor in writing the manuscript. SB interpreted the genetic data and reviewed the paper. LDA interpreted the genetic data and reviewed the paper. LP1 performed clinical evaluation of the proband, collected the patient data and was a major contributor in writing the manuscript. LP2 performed clinical evaluation of the proband and reviewed the paper. VR performed clinical evaluation of the proband and was a major contributor in writing the manuscript. MM performed the genetic test and reviewed the paper. KJ1 performed the genetic test and reviewed the paper. KJ2 was responsible for the clinical interpretation of the testing results and reviewed the paper. LC reviewed the paper. MB made substantial contributions to the conception of the work and reviewed the paper. All authors read and approved the final manuscript.

\section{Funding}

This work was supported by Slovak Research and Development Agency under the Contract No. APW-16-0106. The funding body had no role in the design of this study, collection, analysis, or interpretation of data and in writing the manuscript.

\section{Availability of data and materials}

The datasets generated and/or analysed during the current study are available in ClinVar Database (https://www.ncbi.nlm.nih.gov/), c.1196_1202del; p.(Thr399Lysfs*11); ClinVar accession SCV001426409 and c.11310_11313del; p.(Glu3771Trpfs*18); ClinVar accession SCV001426410. Sequence analyses were performed using NCBI Reference Sequence database, GenBank: NM_015120.4. NGS and Sanger sequencing data of the proband and their relatives can be found as supplementary files.

\section{Ethics approval and consent to participate}

This study is a retrospective case report that does not require ethics committee approval. Written informed consent to participate in this study was obtained from both of the proband's parents. The research complied with the tenets of the Declaration of Helsinki.

\section{Consent for publication}

Written informed consent was obtained from the individual(s), and minor(s)' legal guardian/next of kin, for the publication of any potentially identifiable images or data included in this article.

\section{Competing interests}

The authors declare that they have no conflicts of interest.

\section{Author details}

'Department of Experimental Medicine, Laboratory of Biochemistry, University of Perugia, Perugia, Italy. ${ }^{2}$ Génius n. o, Trnava, Slovakia. ${ }^{3}$ MAGl's Lab, Genetic Testing Laboratory, Via Delle Maioliche 57/D, 38068 Rovereto, TN, Italy. ${ }^{4}$ MAGI Euregio, Via Maso della Pieve, 60/A, 39100 Bolzano, Italy. ${ }^{5}$ Department of Pediatrics, National Institute for Sick Children, Commenius University, Bratislava, Slovakia. ${ }^{6}$ Institute of Histology and Embryology, Faculty of Medicine, Commenius University, Bratislava, Slovakia. ${ }^{7}$ Asper Biogene LLC, Tartu, Estonia. ${ }^{8}$ Department of Ophthalmology, San Paolo Hospital, University of Milan, Milan, Italy.

Received: 8 April 2020 Accepted: 26 August 2020

Published online: 01 September 2020

\section{References}

1. Collin GB, Marshall JD, Ikeda A, So WV, Russell-Eggitt I, Maffei P, et al. Mutations in ALMS1 cause obesity, type 2 diabetes and neurosensory degeneration in Alström syndrome. Nat Genet. 2002;31:74-8.

2. Edwards NC, Moody WE, Yuan M, Warfield AT, Cramb R, Paisey RB, et al. Diffuse left ventricular interstitial fibrosis is associated with sub-clinical myocardial dysfunction in Alström syndrome: an observational study. Orphanet J Rare Dis. 2015;10:1-11.

3. Marshall JD, Beck S, Maffei P, Naggert JK. Alström syndrome. Eur J Hum Genet. 2007:15:1193-202

4. Jaykumar AB, Caceres PS, King-Medina KN, Liao T-D, Datta I, Maskey D, et al. Role of Alström syndrome 1 in the regulation of blood pressure and renal function. JCl Insight. 2018;3:1-17.

5. Nesmith JE, Hostelley TL, Leitch CC, Matern MS, Sethna S, McFarland R, et al. Genomic knockout of alms1 in zebrafish recapitulates Alström syndrome and provides insight into metabolic phenotypes. Hum Mol Genet. 2019;00: $1-12$.

6. Marshall JD, Bronson RT, Collin GB, Nordstrom AD, Maffei P, Paisey RB, et al. New Alström syndrome phenotypes based on the evaluation of 182 cases. Arch Intern Med. 2005;165:675-83.

7. Andersen JS, Wilkinson CJ, Mayor T, Mortensen P, Nigg EA, Mann M. Proteomic characterization of the human centrosome by protein correlation profiling. Nature. 2003:426:570-4.

8. Hearn T, Spalluto C, Phillips VJ, Renforth GL, Copin N, Hanley NA, et al. Subcellular localization of ALMS1 supports involvement of centrosome and basal body dysfunction in the pathogenesis of obesity, insulin resistance, and type 2 diabetes. Diabetes. 2005:54:1581-7.

9. Badano JL, Mitsuma N, Beales PL, Katsanis N. The ciliopathies: an emerging class of human genetic disorders. Annu Rev Genomics Hum Genet. 2006;7 125-48.

10. Hildebrandt F, Benzing T, Katsanis N. Ciliopathies. N Engl J Med. 2011;364: 1533-43.

11. Reiter JF, Leroux MR. Genes and molecular pathways underpinning ciliopathies. Nat Rev Mol Cell Biol. 2017;18:533-47.

12. Satir P, Christensen ST. Overview of structure and function of mammalian cilia. Annu Rev Physiol. 2007:69:377-400.

13. Singla V, Reiter JF. The primary cilium as the cell's antenna: signaling at a sensory organelle. Science. 2006;313:629-33.

14. Davenport JR, Watts AJ, Roper VC, Croyle MJ, van Groen T, Wyss JM, et al. Disruption of intraflagellar transport in adult mice leads to obesity and slow-onset cystic kidney disease. Curr Biol. 2007;17:1586-94.

15. Waldman M, Han JC, Reyes-Capo DP, Bryant J, Carson KA, Turkbey B, et al. Alström syndrome: renal findings in correlation with obesity, insulin resistance, dyslipidemia and cardiomyopathy in 38 patients prospectively evaluated at the NIH clinical center. Mol Genet Metab. 2018:125:181-91.

16. Louw JJ, Corveleyn A, Jia Y, labal S, Boshoff D, Gewillig M, et al. Homozygous loss-of-function mutation in ALMS1 causes the lethal disorder mitogenic cardiomyopathy in two siblings. Eur J Med Genet. 2014;57:532-5. 
17. Shenje LT, Andersen P, Halushka MK, Lui C, Fernandez L, Collin GB, et al. Mutations in Alström protein impair terminal differentiation of cardiomyocytes. Nat Commun. 2014;5:3416.

18. Li G, Vega R, Nelms K, Gekakis N, Goodnow C, McNamara P, et al. A role for Alström syndrome protein, alms1, in kidney ciliogenesis and cellular quiescence. PLoS Genet. 2007;3:e8.

19. Knorz VJ, Spalluto C, Lessard M, Purvis TL, Adigun FF, Collin GB, et al. Centriolar association of ALMS1 and likely centrosomal functions of the ALMS motif-containing proteins C10orf90 and KIAA1731. Mol Biol Cell. 2010; 21:3617-29.

20. Collin GB, Marshall JD, King BL, Milan G, Maffei P, Jagger DJ, et al. The Alström syndrome protein, ALMS1, interacts with a-actinin and components of the endosome recycling pathway. PLoS One. 2012;7:e37925.

21. Hearn T. ALMS1 and Alström syndrome: a recessive form of metabolic, neurosensory and cardiac deficits. J Mol Med (Berl). 2019;97:1-17.

22. Favaretto F, Milan G, Collin GB, Marshall JD, Stasi F, Maffei P, et al. GLUT4 defects in adipose tissue are early signs of metabolic alterations in Alms1GT/GT, a mouse model for obesity and insulin resistance. PLoS One. 2014;9:e109540.

23. Leitch CC, Lodh S, Prieto-Echagüe V, Badano JL, Zaghloul NA. Basal body proteins regulate notch signaling through endosomal trafficking. J Cell Sci. 2014;127(Pt 11):2407-19.

24. Zulato E, Favaretto F, Veronese C, Campanaro S, Marshall JD, Romano S, et al. ALMS1-deficient fibroblasts over-express extra-cellular matrix components, display cell cycle delay and are resistant to apoptosis. PLoS One. 2011;6:e19081.

25. Möller A, Xie SQ, Hosp F, Lang B, Phatnani HP, James S, et al. Proteomic analysis of mitotic RNA polymerase II reveals novel interactors and association with proteins dysfunctional in disease. Mol Cell Proteomics. 2012;11:M111.011767.

26. Pereiro I, Hoskins BE, Marshall JD, Collin GB, Naggert JK, Piñeiro-Gallego T, et al. Arrayed primer extension technology simplifies mutation detection in Bardet-Biedl and Alström syndrome. Eur J Hum Genet. 2011;19:485-8.

27. Aldrees A, Abdelkader E, Al-Habboubi H, Alrwebah H, Rahbeeni Z, Schatz P. Non-syndromic retinal dystrophy associated with homozygous mutations in the ALMS1 gene. Ophthalmic Genet. 2019;40:77-9.

28. Nerakh G, Ranganath P. Alström syndrome presenting as isolated dilated cardiomyopathy. Indian J Pediatr. 2019;86:296-8.

29. Marshall JD, Muller J, Collin GB, Milan G, Kingsmore SF, Dinwiddie D, et al. Alström syndrome: mutation Spectrum of ALMS1. Hum Mutat. 2015;36:6608.

30. Maltese PE, larossi G, Ziccardi L, Colombo L, Buzzonetti L, Crinò A, et al. A next generation sequencing custom gene panel as first line diagnostic tool for atypical cases of syndromic obesity: application in a case of Alström syndrome. Eur J Med Genet. 2018;61:79-83.

31. Wang $X$, Wang H, Cao M, Li Z, Chen X, Patenia C, et al. Whole-exome sequencing identifies ALMS1, IQCB1, CNGA3, and MYO7A mutations in patients with leber congenital amaurosis. Hum Mutat. 2011;32:1450-9.

32. Das Bhowmik A, Gupta N, Dalal A, Kabra M. Whole exome sequencing identifies a homozygous nonsense variation in ALMS1 gene in a patient with syndromic obesity. Obes Res Clin Pract. 2017;11:241-6.

33. Kılınç S, Yücel-Yılmaz D, Ardagil A, Apaydın S, Valverde D, Özgül RK, et al. Five novel ALMS1 gene mutations in six patients with Alström syndrome. J Pediatr Endocrinol Metab. 2018;31:681-7.

34. Paisey RB, Geberhiwot T, Waterson M, Cramb R, Steeds R, Williams K, et al. Modification of severe insulin resistant diabetes in response to lifestyle changes in Alström syndrome. Eur J Med Genet. 2014;57:71-5.

35. Casey J, McGettigan P, Brosnahan D, Curtis E, Treacy E, Ennis S, et al. Atypical Alstrom syndrome with novel ALMS1 mutations precluded by current diagnostic criteria. Eur J Med Genet. 2014;57:55-9. https://doi.org/10. 1016/j.ejmg.2014.01.007.

36. Lazar CH, Kimchi A, Namburi P, Mutsuddi M, Zelinger L, Beryozkin A, et al. Nonsyndromic early-onset cone-rod dystrophy and limb-girdle muscular dystrophy in a consanguineous Israeli family are caused by two independent yet linked mutations in ALMS1 and DYSF. Hum Mutat. 2015;36: 836-41.

37. Sanchez-Navarro I, da Silva LRJ, Blanco-Kelly F, Zurita O, Sanchez-Bolivar N, Villaverde $\mathrm{C}$, et al. Combining targeted panel-based resequencing and copy-number variation analysis for the diagnosis of inherited syndromic retinopathies and associated ciliopathies. Sci Rep. 2018;8:5285.
38. Castro-Sánchez S, Álvarez-Satta M, Tohamy MA, Beltran S, Derdak S, Valverde D. Whole exome sequencing as a diagnostic tool for patients with ciliopathy-like phenotypes. PLoS One. 2017;12:e0183081.

39. Kopanos C, Tsiolkas V, Kouris A, Chapple CE, Albarca Aguilera M, Meyer R, et al. VarSome: the human genomic variant search engine. Bioinformatics. 2019;35:1978-80.

40. Marshall JD, Maffei P, Collin GB, Naggert JK. Alström syndrome: genetics and clinical overview. Curr Genomics. 2011;12:225-35.

41. Schweingruber C, Rufener SC, Zünd D, Yamashita A, Mühlemann O. Nonsense-mediated mRNA decay - mechanisms of substrate mRNA recognition and degradation in mammalian cells. Biochim Biophys Acta. 1829;2013:612-23.

42. Lombardo B, D'Argenio V, Monda E, Vitale A, Caiazza M, Sacchetti L, et al. Genetic analysis resolves differential diagnosis of a familial syndromic dilated cardiomyopathy: a new case of Alström syndrome. Mol Genet genomic Med. 2020;8:e1260.

43. Paisey RB, Steeds R, Barrett T, Williams D, Geberhiwot T, Gunay-aygun M. Alström Syndrome Summary Genetic counseling Diagnosis Suggestive Findings; 2020. p. 1-28.

44. Lam DW, LeRoith D. Metabolic Syndrome. In: Feingold KR, Anawalt B, Boyce A, Chrousos G, de Herder WW, Dungan K, Grossman A, Hershman JM, Hofland HJ, Kaltsas G, Koch C, Kopp P, Korbonits M, McLachlan R, Morley JE, New M, Purnell J, Singer F, Stratakis CA, Trence DL, Wilson DP, editors. Endotext [Internet]. South Dartmouth (MA): MDText.com, Inc.; 2019.

45. Mannu GS, Zaman MJS, Gupta A, Rehman HU, Myint PK. Evidence of lifestyle modification in the management of hypercholesterolemia. Curr Cardiol Rev. 2013;9:2-14

46. Khan MU. Lifestyle modification in the prevention of type II diabetes mellitus. Oman Med J. 2012;27:170-1.

47. Rhee E-J, Kim HC, Kim JH, Lee EY, Kim BJ, Kim EM, et al. 2018 guidelines for the management of dyslipidemia. Korean J Intern Med. 2019;34:723-71.

48. Chobanian AV, Bakris GL, Black HR, Cushman WC, Green LA, Izzo JL, et al. Seventh report of the Joint National Committee on Prevention, Detection, Evaluation, and Treatment of High Blood Pressure. Hypertens (Dallas, Tex 1979). 2003;42:1206-52..

49. Executive summary. Standards of medical care in diabetes--2012. Diabetes Care. 2012;35(Suppl 1):S4-10

50. Torkamandi S, Rezaei S, Mirfakhraei R, Askari M, Piltan S, Gholami M. Whole exome sequencing identified two homozygous ALMS1 mutations in an Iranian family with Alström syndrome. Gene. 2020;727:144228..

\section{Publisher's Note}

Springer Nature remains neutral with regard to jurisdictional claims in published maps and institutional affiliations.
Ready to submit your research? Choose BMC and benefit from:

- fast, convenient online submission

- thorough peer review by experienced researchers in your field

- rapid publication on acceptance

- support for research data, including large and complex data types

- gold Open Access which fosters wider collaboration and increased citations

- maximum visibility for your research: over $100 \mathrm{M}$ website views per year

At BMC, research is always in progress.

Learn more biomedcentral.com/submissions 